\title{
Formação permanente, flexível e a distância pela Internet: Curso de Gestão Descentralizada de Recursos Humanos em Saúde ${ }^{1}$
}

\author{
Miriam Struchiner, ${ }^{2}$ Maria Alice Roschke ${ }^{3}$ \\ e Regina Maria Vieira Ricciardi ${ }^{4}$
}

RESUMO O presente trabalho descreve o Curso de Gestão Descentralizada de Recursos Humanos em Saúde, um programa de educação a distância baseado na Internet para a formação e a educação continuada de profissionais de saúde. Este curso, uma iniciativa da Organização Pan-Americana da Saúde, visa atender às exigências de formar profissionais autônomos, que possam se atualizar constantemente sem terem de se afastar de seus locais de trabalho. O modelo proposto estimula um processo educativo que integra teoria e prática em contextos realistas e relevantes e que potencializa a participação ativa dos alunos, individual e coletivamente. O curso vem sendo submetido a uma série de estudos pilotos no Brasil, no Chile e no Peru. Depois dessas avaliações, uma série de adaptações vêm sendo feitas para facilitar a implementação definitiva do curso e para possibilitar a adequação dos conteúdos às reais condições de cada país.

Palavras chave Reforma do setor saúde, educação continuada.

Uma das condições essenciais para a reforma do setor saúde é a formação e educação permanente da força de trabalho, que deve estar preparada para enfrentar mudanças constantes e para acompanhar produtivamente o acelerado avanço científico e tecnológico da sociedade contemporânea. Nesse sentido, o processo educativo, em todos

1 O projeto recebeu apoio institucional da Organização Pan-Americana da Saúde.

2 Universidade Federal do Rio de Janeiro, Laboratório de Tecnologias Cognitivas. Correspondência e pedidos de separatas devem ser enviados a: Núcleo de Tecnologia Educacional para a Saúde (NUTES), Universidade Federal do Rio de Janeiro, Cidade Universitária, Ilha do Fundão, CCS, Bloco A, Sala A026, CEP 21949-900, Rio de Janeiro, RJ, Brasil. E-mail: mchiner@nutes.ufri.br

3 Organização Panamericana da Saúde, Divisão de Recursos Humanos, Washington, DC, Estados Unidos da América. E-mail: roschkem@paho.org

4 Universidade Federal do Rio de Janeiro, Laboratório de Tecnologias Cognitivas. E-mail: ricciardi@ nutes.ufrj.br os seus níveis, integrando ensino, investigação e prática, torna-se um elemento estratégico.

No entanto, a educação (formal e continuada) no campo da saúde raramente privilegia um enfoque que possibilite a estudantes e profissionais a oportunidade de vivenciar ativamente a aprendizagem como construção de conhecimento, por meio da reflexão sobre suas próprias experiências, bem como a participação ativa em estudos, investigações e foros de debate. Por outro lado, a disseminação de novos conhecimentos científicos está pouco orientada para a prática profissional, havendo, inclusive, um longo período de defasagem entre a sua produção e difusão e a sua integração ao cotidiano dos serviços de saúde. Do ponto de vista pedagógico, participantes de programas de formação são expostos a métodos de ensino reprodutivistas, que conduzem à passividade e à superficialidade, assim como à falta de criatividade, de curiosidade e de compreensão sobre os fenômenos e as experiências vivenciados.

É fundamental, portanto, que sejamos capazes de vencer os atuais desafios da educação permanente em saúde, compartilhando e tornando acessível o conhecimento científico produzido na solução de problemas do setor saúde e preparando os profissionais para continuarem aprendendo ao longo de suas vidas. Esses desafios tornam-se ainda mais complexos quando pensamos na grande massa de profissionais que trabalham em diferentes países da América Latina, com formação diferenciada, e que enfrentam problemas de saúde desencadeados pelas diferenças sociais, a maioria das vezes em condições precárias de infra-estrutura. 
Como podemos, então, promover mudança? Como desenvolver projetos e materiais que levem em consideração as necessidades específicas de cada região e que compartilhem democraticamente as novas informações e conhecimentos? Como promover um maior intercâmbio de experiências, de materiais educativos e de informações entre os centros de ensino e investigação em saúde e os serviços, assim como uma maior integração entre os países da América Latina? Como possibilitar que essas atividades, além de cumprir com seus objetivos primordiais, contribuam para a inserção dos serviços de saúde na nova ordem social desencadeada pela sociedade de informação?

Educação a distância e educação permanente não são conceitos novos. No entanto, apesar do entusiasmo dos anos 1970, quando se multiplicaram os programas auto-instrucionais, os resultados dessas modalidade educativas não têm sido satisfatórios, em conseqüência não somente dos altos custos de produção e de difusão dos materiais, mas também de questões pedagógicas e metodológicas.

De um modo geral, os modelos tradicionais de educação permanente e a distância seguiam concepções de correntes pedagógicas como mastery learning, ou "aprendizagem para domínio individual do conteúdo", onde os currículos e materiais educativos eram organizados em módulos por objetivos comportamentais, que deveriam ser seqüencialmente alcançados pelos participantes. Esse modelo, especialmente quando utilizado a distância, apresenta sérias limitações para o desenvolvimento de um processo educativo construtivo (1). Primeiro, porque o material é oferecido principalmente por meio impresso e, na maioria das vezes, as relações com os centros produtores dos cursos ou com os tutores são realizadas por correio, limitando os objetivos educacionais a níveis elementares e descritivos. No caso da educação permanente em serviços de saúde, os objetivos se tornam ainda mais limitados, devido à necessidade de integrar teoria e prática tendo como foco os problemas cotidianos (a inte- gração de conhecimentos de diferentes áreas para a resolução de problemas e a tomada de decisões mediante análise, avaliação e síntese). Na maioria das vezes, os modelos fechados, como o de aprendizagem para domínio individual do conteúdo, não oferecem espaços adequados para a aprendizagem a partir de problemas concretos ou exemplos baseados nas realidades locais. Não estimulam a busca ativa e a manipulação de informações das mais diversas naturezas e formatos, impossibilitando uma aprendizagem significativa (meaningful learning), em consonância com os desafios impostos pela sociedade da informação. ${ }^{5}$

Por outro lado, a psicologia cognitiva nos tem mostrado que os indivíduos aprendem de forma não-seqüencial e a partir de uma visão holística (em contraposição à abordagem fragmentada). Diferem, também, nos caminhos processados para a construção de seu próprio conhecimento (2). Em termos dos profissionais de saúde, a necessidade de desenvolver um processo educativo e materiais que possibilitem ao aprendiz trabalhar em seu próprio ritmo e de acordo com seu estilo de aprendizagem é especialmente crítica, já que estamos lidando com uma população de adultos.

Finalmente, é fundamental ressaltar a importância do espaço social da aprendizagem — ou seja, a interação, $o$ diálogo educacional e o intercâmbio de idéias e experiências entre tutores e orientadores e profissionais de saúde e entre os participantes de atividades educativas - como elemento essencial do processo de construção do conhecimento. Tal espaço é praticamente inexistente quando se trabalha com modelos tradicionais de capacitação a distância, por sua natureza impessoal.

A partir dessas considerações, passamos a explorar e investigar o uso de novas tecnologias de informação, especificamente as redes de informática e os serviços da Internet, como um novo espaço pedagógico. $\mathrm{O}$ uso de

\footnotetext{
5 Novak JD. A theory of education [documento mimeografado]. Ithaca, NY: Cornell University (draft, 2nd edition); 1992.
}

redes informatizadas possibilita que os profissionais e as equipes de saúde, sem necessidade de se afastarem dos serviços, participem de um processo de aprendizagem significativa, tanto individualmente (por meio de orientações individualizadas e do acesso a materiais e informações) como coletivamente (por meio de grupos de discussão, de intercâmbio de experiências, de espaços abertos e orientados de reflexão, de projetos coletivos).

Portanto, um programa de educação permanente a distância em saúde com o uso de redes deve ser compreendido como um novo paradigma para a organização social de um campo de conhecimentos e práticas, com perspectivas de formação continuada e intercâmbios de experiências. Configura-se, assim, como um espaço aberto e flexível, permitindo a participação ativa de todos os seus integrantes.

A tecnologia educacional em saúde, apoiada em uma reflexão sobre a filosofia, a estrutura, o conteúdo e a metodologia do processo educativo, busca explorar a introdução de novas alternativas para tal construção, incorporando avanços tecnológicos e fundamentos científicos de diferentes campos do saber que oferecem novas perspectivas e novos espaços para a formação de profissionais da saúde.

\section{O CURSO DE GESTÃO DESCENTRALIZADA DE RECURSOS HUMANOS EM SAÚDE}

É nesse contexto que se insere o Curso de Gestão Descentralizada de Recursos Humanos em Saúde (CGDRHS) aqui descrito. Esse curso foi desenvolvido como parte do Programa de Aprendizagem a Distância em Recursos Humanos em Saúde (PADRHUS) da Organização Pan-Americana da Saúde (OPAS). O projeto de desenvolvimento contou, inicialmente, com a participação de Brasil, Chile e Peru, que contribuíram para a definição dos problemas da gestão de recursos humanos e para a programação dos conteúdos. O CGDRHS estabelece uma 
proposta de base construtivista para a formação a distância de profissionais de saúde, utilizando sistemas de comunicação eletrônica e a Internet. Seu objetivo é contribuir para a transformação e o aprimoramento da organização do trabalho em saúde no marco da reforma sanitária dos países da América Latina e, portanto, para a melhoria da qualidade da atenção à população assistida.

A OPAS oferece o curso aos países interessados através do seu processo de cooperação técnica. A instituição responsável pelo processo de implementação e gestão educativa e administrativa do curso é definida em conjunto com especialistas em recursos humanos em cada país. Em geral, o curso é implementado em instituições educativas de nível superior ou divisões de recursos humanos dos ministérios de saúde ou seguridade social. Durante esse processo, a OPAS se responsabiliza pela capacitação pedagógica dos coordenadores e orientadores (docentes) do curso e pela instalação do programa de computador necessário para o curso em um servidor local. O país assume os custos de implementação, que incluem um domínio na Internet, tempo online para orientadores e participantes e apoio técnico de um administrador de web.

Os participantes e os orientadores são selecionados em cada país pelas pessoas responsáveis pelo desenvolvimento de recursos humanos e pelas autoridades responsáveis na instituição que promove o curso. Os participantes recebem um certificado da instituição que administra o curso. Futuramente, o curso poderá ser oferecido como uma disciplina em programas de mestrado em instituições interessadas. Atualmente, o curso se encontra em funcionamento no Brasil, Chile e Peru, e está em desenvolvimento na Costa Rica e no Equador (os casos e problemas de gestão são analisados e transformados ou novos casos são elaborados para atender às necessidades do contexto de cada país). Durante o processo de implementação nesses dois países, participarão representantes de outros países interessados.

\section{Enfoque metodológico}

$\mathrm{O}$ enfoque pedagógico proposto para o presente projeto de educação a distância fundamentou-se nos princípios básicos do construtivismo (3-5). $\mathrm{O}$ construtivismo tem como premissa fundamental a idéia de que o indivíduo é agente ativo de seu próprio conhecimento, isto é, constrói significados e define o seu próprio sentido e representação da realidade de acordo com suas experiências e vivências em diferentes contextos. Essas representações, no entanto, estão constantemente abertas a mudanças e suas estruturas formam as bases sobre as quais novos conhecimentos são construídos (6).

Esse enfoque distancia-se da idéia de que o conhecimento acumulado possa ser compreendido e compartilhado através da mera transmissão de informações e de uma visão linear e simplificada dos fenômenos envolvidos, como se suas manifestações fossem imperiosamente as mesmas, independentemente do contexto. Assume que o processo de formação tem como eixo fundamental o pensamento crítico e produtivo e a atividade consciente e intencional do aluno na resolução de problemas do mundo real em diversas instâncias (técnica, interpessoal, política, etc.).

As experiências vivenciadas por profissionais de saúde, tanto como cidadãos usuários da rede pública ou privada de saúde ou através da mídia que veicula notícias sobre o setor, quanto a partir do conhecimento técnicocientífico adquirido nos períodos de formação e no exercício da prática profissional, constituem o universo de experiências que contribuem para as representações e conseqüentes atuações no campo da gestão de recursos humanos.

É nesse sentido que o enfoque aqui discutido torna-se essencialmente interessante para a educação permanente em saúde: o profissional é um adulto cuja natureza e formação lhe conferem uma série de experiências e representações, que estão em constante processo de transformação (assimilação/ acomodação) através das vivências pessoais, da troca com outros profissio- nais direta ou indiretamente envolvidos com as atividades que exerce e da interação com a realidade apresentada pela população alvo. Cada atividade ou procedimento novo necessita ser pensado de forma a viabilizar sua integração e renovação na prática. Não é possível acreditar que procedimentos inovadores, ou mesmo normativos, por exemplo, possam ser incorporados simplesmente a partir de uma regulamentação transmitida de cima para baixo. Qualquer inovação deve ser compreendida no âmbito das vivências, experiências e necessidades do contexto, tanto em suas formas de aplicação, como no compartilhamento com os atores envolvidos no processo. Tal enfoque ultrapassa a visão de um programa de capacitação específico, indica uma postura em relação ao conhecimento e possibilita uma organização do trabalho onde formação e produção de serviços possam estar intimamente integrados.

As tecnologias modernas de informação e comunicação, como os serviços oferecidos pela Internet, teleconferência, listas de discussão, conversações em tempo real (chat), correio eletrônico, entre outros, além do acesso a grande quantidade de informações, oferecem e ampliam os recursos necessários à formação de ambientes cooperativos e construtivistas de aprendizagem a distância. O profissional pode ter acesso a conhecimentos novos e trocar informações e experiências sem a necessidade de afastar-se de sua própria realidade, buscando em sua vivência pessoal e social no ambiente de trabalho elementos que contribuam para a resolução dos problemas de outros serviços, bem como a avaliação intensiva e incorporação de novas soluções ao seu local de atuação.

Do ponto de vista pedagógico, Cunningham et al. (5) definem como finalidades de um ambiente construtivista de aprendizagem os seguintes princípios $(5,7)$ :

- possibilitar que o participante experimente o processo de construção do conhecimento, assumindo a responsabilidade pela decisão dos conteúdos e dos métodos de estudo; 
- oferecer experiência e múltiplas representações dos fenômenos e problemas estudados;

- envolver a aprendizagem em contextos realistas e relevantes, isto é, mais autênticos em relação às tarefas da aprendizagem;

- encorajar "apropriação" e "voz" no processo de aprendizagem, colocando o professor ou tutor no papel de consultor que auxilia os participantes a organizarem seus objetivos e caminhos na aprendizagem;

- envolver a aprendizagem em experiências sociais, incentivando a cooperação professor-aluno e aluno-aluno;

- e encorajar a auto-conscientização do participante sobre o processo de construção de conhecimento, para que compreenda como aprende e seja capaz de explicar por que e como um determinado problema foi resolvido.

Utilizando esse enfoque teóricometodológico, todas as características e os elementos discutidos foram levados em conta na concepção, estruturação e modelagem do ambiente de aprendizagem do CGDRHS, de forma a conformá-lo como um ambiente construtivista de aprendizagem.

\section{Distribuição e gerência}

Devido à abordagem educativa adotada no CGDRHS e à finalidade do Programa de Desenvolvimento de Recursos Humanos da OPAS, de facilitar o desenvolvimento de capacidades em todos os países da América Latina e do Caribe, tendo em conta as especificidades locais, ficou definido que a gerência do curso de gestão seria descentralizada nas diferentes regiões, tendo em vista as condições técnicas e de recursos humanos para assumir a coordenação e a orientação da aprendizagem dos alunos. Isso significa que o sistema é distribuído às instituições que se comprometem a formar pessoal qualificado para manejar o sistema, a orientar as atividades e a oferecer oportunidades de participação a um grande número de profissionais de saúde que necessitem aprimoramento nas questões relativas à gestão descentralizada de recursos humanos nas diferentes regiões.

Para orientar o trabalho e auxiliar no manejo do curso, elaborou-se um manual técnico-pedagógico que associa as propostas e funções educativas do programa a seu esquema operacional. Esse material serve, também, para o processo de capacitação de coordenadores e orientadores nos diferentes locais onde o curso é implementado. $\mathrm{O}$ manual é distribuído (nas versões online e em papel) com o sistema computacional que contém o curso.

Para promover a integração das "comunidades de aprendizagem" de gestão de recursos humanos em saúde, está sendo planejado um portal especial com seminários, materiais, avaliações de experiências, avisos, referências e recomendações de outros sites. Essa iniciativa é extremamente importante na consolidação da concepção do sistema de formação de recursos humanos a distância, uma vez que tal sistema deve preservar a identidade e os contextos locais na condução e gestão do curso.

\section{Perfil dos participantes}

O CGDRHS é dirigido prioritariamente a profissionais ligados aos diferentes níveis da rede de serviços de saúde e de manejo básico de grupos e equipes de trabalho em serviços, por exemplo: gerentes de serviços de saúde com potencial para conduzir ou facilitar mudanças na gestão a partir de uma visão da organização dos recursos humanos na atenção à saúde; pessoal de saúde que, por necessidades institucionais ou de desenvolvimento de capacidades, almejem movimentar-se pelos diferentes níveis da rede de atenção e participar na gestão dos recursos humanos em saúde; e indivíduos que queiram formar grupos de trabalho para a gestão de serviços de saúde ou conduzir processos educativos nessa área.

Uma questão fundamental considerada no perfil da população alvo foi sua abrangência, representada por diferentes características culturais no que diz respeito a aspectos de linguagem e formas de comunicação, a valores e conceitos sobre saúde, atenção à população em seus diferentes níveis e gestão de recursos humanos, bem como ao corpo de conhecimentos nesse campo. Isso vale tanto para o âmbito da América Latina (entre países), como para as diferentes localidades, em nível nacional. Portanto, optou-se pela flexibilização do modelo: a definição conceitual do programa (incluindo conteúdos e estratégias de aprendizagem), de sua base tecnológica e de materiais e atividades está sendo produzida de forma que esses itens possam ser adaptados e utilizados de diferentes formas em diversos contextos.

\section{Configuração básica da interface}

A configuração central do programa está baseada em um material educativo estruturado a partir de três elementos: base conceitual; teorias e funções relacionadas ao exercício da gestão de recursos humanos; e problemas "reais" ligados à prática da gestão em diferentes contextos e níveis central, regional e local. As três partes básicas estão interrelacionadas por meio de palavraschave no corpo do texto e menus. Assim, o participante do programa pode navegar livremente, buscando informações, trabalhando individualmente ou em grupo, orientando-se com colegas e especialistas. Além dessas atividades e materiais, os alunos têm oportunidade de acessar informações, perguntas freqüentes, glossário e referências bibliográficas e de participar de fóruns de discussão.

Para dar conta dessa estrutura e para melhor orientação do usuário, a concepção da interface seguiu uma lógica baseada nos diferentes contextos do ambiente. Ou seja, o programa oferece um "contexto global" onde todas as funções e atividades pertinentes ao programa em geral, como pasta de trabalhos, ajuda, orientação/tutoria, avaliação, calendário/eventos, referências bibliográficas, compõem um menu de opções que pode ser acessado de qualquer outro contexto/tela. Além disso, o programa oferece contextos especí- 
FIGURA 1. Tela típica de conteúdo do ambiente do Curso de Gestão Descentralizada de Recursos Humanos em Saúde

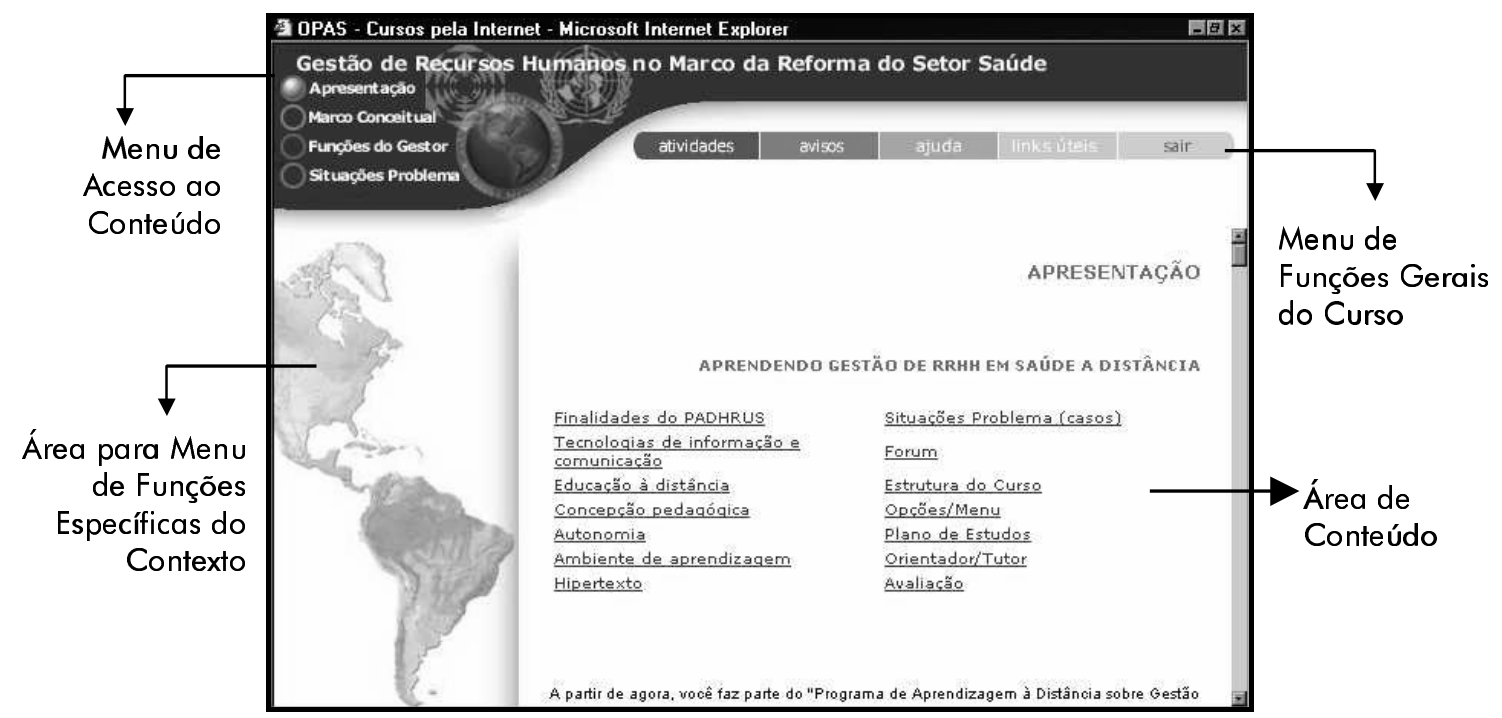

ficos, que contam com funções próprias e inerentes às suas estruturas e finalidades, como é o caso dos três eixos fundamentais do programa: marco conceitual, funções do gestor e situações-problema (figura 1).

Além dos alunos, são usuárioschave do sistema os orientadores, os coordenadores de curso e os administradores da rede. Cada um desses usuários tem funções diferenciadas que correspondem a distintas configurações de interface, especialmente planejadas e implementadas no sistema. Assim sendo, o ambiente do curso na Internet foi desenvolvido com o propósito de oferecer uma interface fácil de ser compreendida e utilizada por participantes com diferentes níveis de experiência no uso da rede e de computadores. Por isso, seu projeto priorizou a criação de um ambiente praticamente auto-explicativo e atraente, além de extremamente flexível e passível de modificações e adaptações. Com base nesses princípios, foram concebidas quatro interfaces, cada qual com conteúdo e atividades básicas comuns (ambiente básico do aluno e demais usuários) e com um ambiente específico para cada uma das funções: coordenador de curso (normalmente uma pessoa), orientadores (um orientador para cada 20 a 30 alunos, de acordo com as possibilidades da insti- tuição) e administrador da rede (um profissional). Esse modelo pode ser melhor compreendido se levarmos em consideração o fato de que não se pretende centralizar o curso na América Latina, mas possibilitar gestão própria, com possibilidade de adaptar o conteúdo à realidade de cada contexto onde será utilizado.

O administrador do site é um técnico em informática que exerce funções de organização, acompanhamento, gerenciamento e manutenção do sistema computacional e seu funcionamento, para o bom andamento do curso do ponto de vista técnico. Deve estar preparado para acompanhar o fluxo das informações e para auxiliar alunos, orientadores e coordenadores sobre aspectos técnico-operacionais do uso do programa (figura 2).

O coordenador do curso é um profissional especializado na área de conteúdo do curso, com experiência em ensino. Deve estar preparado para gerenciar as atividades pedagógicas, manipulando conteúdo, inserindo ou modificando informações (situaçõesproblema, avisos, calendário), gerenciando foros de discussão entre alunos e acompanhando o trabalho realizado pelos orientadores (figura 3 ).

A abordagem construtivista adotada neste projeto coloca a figura do tradicional tutor no papel de facilita- dor, de orientador das atividades autônomas, individuais ou coletivas, dos alunos. Por isso, chamamos esse docente de orientador. $\mathrm{O}$ orientador do curso é um profissional da área da saúde que acompanhará o progresso e o trabalho desenvolvido pelos seus orientandos, em grupo ou individualmente. Deve estar preparado para negociar e trocar com seus alunos, incentivá-los a participar, avaliar suas atividades e para trabalhar interativamente (figura 4).

\section{Orientação ou tutoria}

Os participantes do CGDRHS são orientados e traçam seus planos de trabalho juntamente com os orientadores, que os acompanharão ao longo do processo. Os orientadores devem ser profissionais com domínio do conteúdo tanto do ponto de vista teórico quanto prático. São orientados quanto ao modelo do programa educativo, às atividades pedagógicas e ao desenvolvimento de suas funções de orientador. Para isso, um programa de capacitação de orientadores deve ser organizado pelo grupo de coordenação do curso de educação a distância.

O papel exercido pelo orientador é fundamental quando a proposta educativa do programa de educação a 


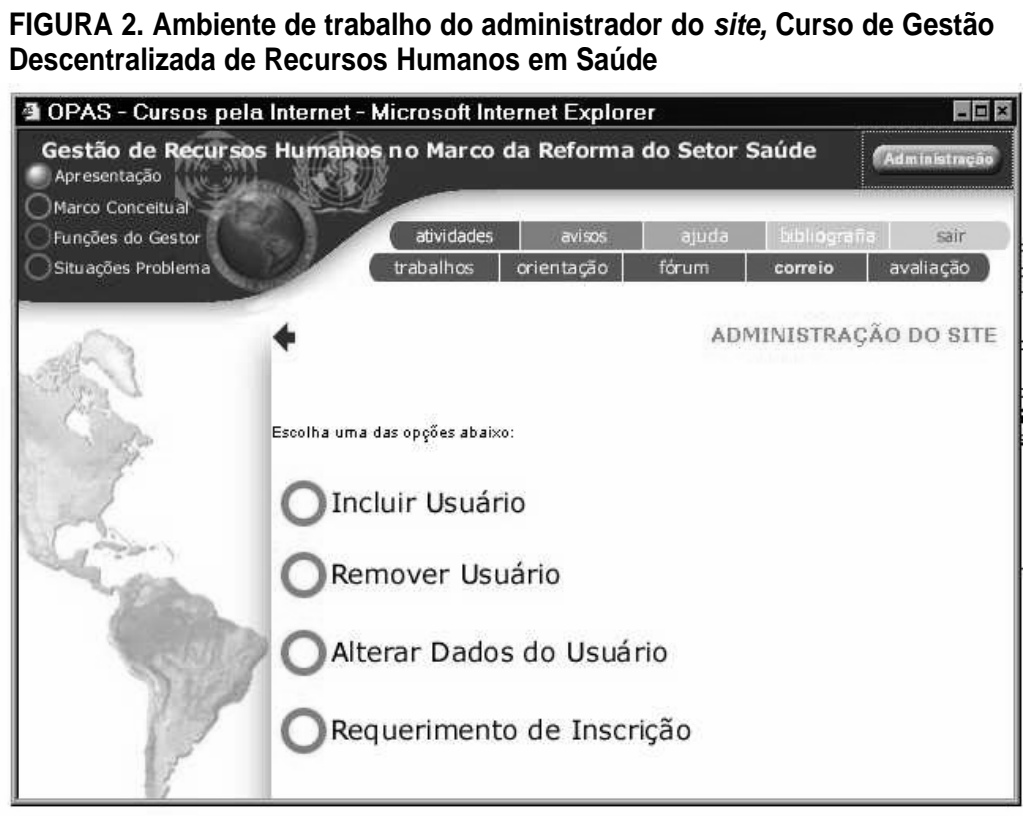

FIGURA 3. Tela de entrada no ambiente de trabalho do coordenador, Curso de Gestão Descentralizada de Recursos Humanos em Saúde

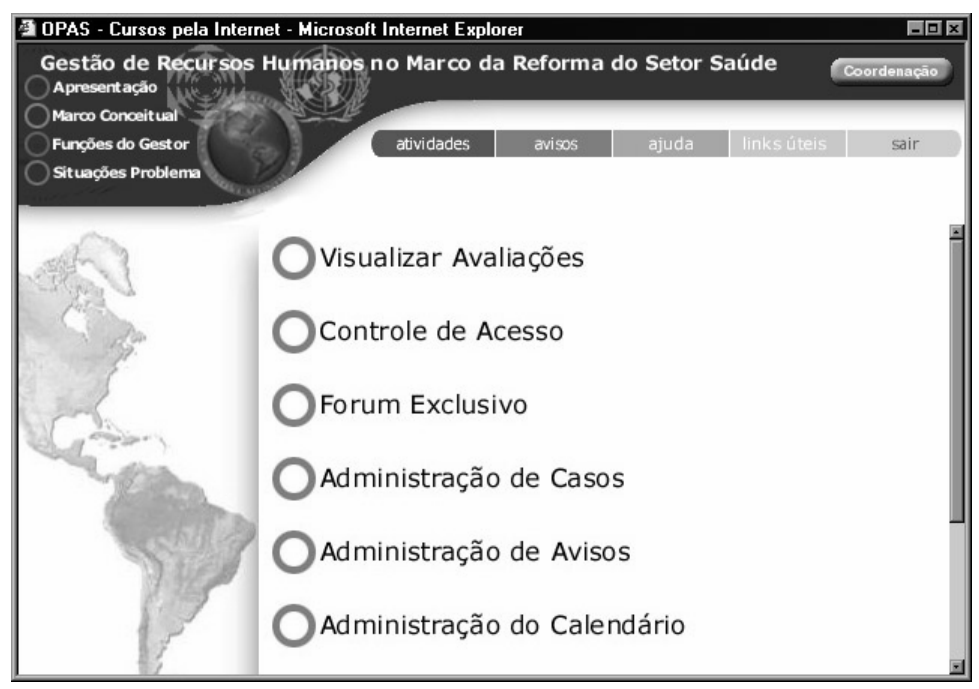

distância está pautada pela autoaprendizagem, inter-aprendizagem e pelo papel ativo do sujeito aprendiz e, principalmente, quando o ato educativo é entendido como um momento de construção de conhecimento, de intercâmbio de experiências e criação de novas formas de participação. É a partir desses pressupostos que se desenvolve a reflexão sobre o papel exercido pelo tutor em um ambiente construtivista. Gutierrez e Prieto (8) assinalam seis qualidades indispensáveis ao orientador: possuir clara concepção de aprendizagem; estabelecer relações empáticas com seus interlocutores; sentir o alternativo - partilhar sentido; constituir forte instância de personalização (ou seja, conhecer os alunos suficientemente para apoiar cada um em suas necessidades pessoais de aprendizagem); e facilitar a construção de conhecimento. Essas qualidades garantem o desempenho das seguintes atividades para as quais o orientador deve estar preparado: acompanhar o processo, realizar reuniões grupais, estabelecer redes, retroalimentar, avaliar e construir a memória do processo. Esses elementos serão trabalhados na capacitação dos orientadores, a ser realizada por cada país participante ou por meio de convênios entre países.

\section{ESTRUTURAÇÃO DO CONTEÚDO E ESTRATÉGIAS PEDAGÓGICAS}

O conteúdo do CGDRHS foi estruturado a partir de três eixos fundamentais relacionados entre si: marco conceitual, funções do gestor e casos / situações-problema.

Cada um dos três eixos está associado aos outros por meio de ligações (links), por palavras-chave no corpo do texto ou por meio de menus. Assim, o participante do programa poderá navegar livremente, buscando informações. A estrutura do curso busca, assim, contemplar a diversidade de sua clientela, possibilitando que os recursos sejam explorados sem uma seqüência pré-definida.

\section{Marco conceitual}

O eixo "marco conceitual" consiste em dois textos que oferecem fundamentação teórica para aprofundamento dos temas e problemas da gestão de recursos humanos em saúde.

No primeiro texto, "A saúde no contexto de reforma", são apresentados e discutidos todos os conceitos-chave para a compreensão contextualizada dos problemas de gestão descentralizada de recursos humanos a partir de um embasamento teórico-conceitual abrangente no âmbito das reformas setoriais em curso em nossa sociedade.

O segundo texto, "Recursos humanos nas reformas setoriais", trata especificamente das mudanças ocorridas na gestão de recursos humanos para o setor saúde e nas relações de trabalho decorrentes do processo de reforma. Contém palavras de glossário para facilitar a compreensão dos conceitos fundamentais discutidos no texto e palavras-chave que remetem à leitura 


\section{FIGURA 4. Tela de entrada no ambiente de trabalho do orientador, Curso de Gestão Descentralizada de Recursos Humanos em Saúde}

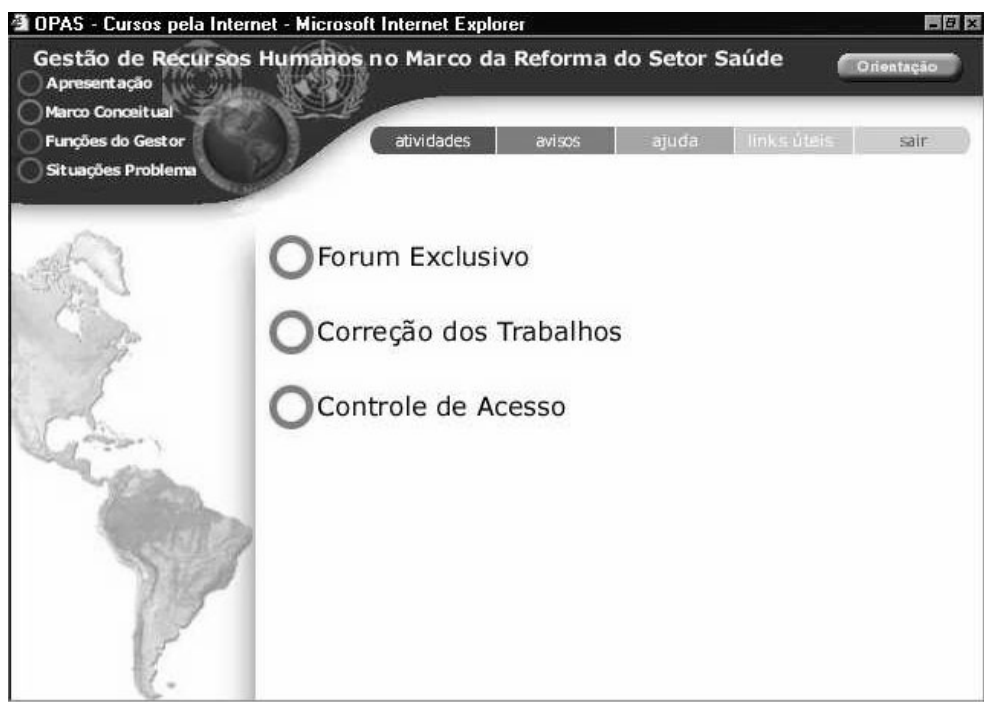

do primeiro texto. Os textos devem ser atualizados periodicamente e cada país pode indicar ou melhorar biografias e links úteis em contextos específicos.

\section{Funções do gestor}

O eixo temático "funções do gestor" define-se a partir de quatro funções básicas: organização do trabalho, administração de pessoal, relações de trabalho e capacitação e ética e responsabilidade. Cada uma dessas funções é apresentada por meio de um texto simples, que procura descrever as principais competências e desafios críticos do gestor de recursos humanos. Os participantes podem, também, acessar as situações-problema relacionadas a cada uma das funções.

\section{Situações-problema}

Este é o eixo central do programa. Todo o conteúdo teórico exposto serve de base para que o participante aprofunde seu conhecimento a partir da discussão e resolução dos casos apresentados. O eixo temático "situaçõesproblema" propõe um conjunto de casos ou problemas baseados em situações reais e associados principalmente às funções e competências de- sempenhadas pelo gestor de recursos humanos.

A estrutura dos casos é formada pelos seguintes elementos: descrição do contexto e da situação-problema; visões do problema (atores envolvidos); referências bibliográficas e outras fontes; casos relacionados; marco conceitual e funções do gestor; orientação (entrar em contato com orientador); acessar perguntas já respondidas sobre o caso; área para resolução de casos.

A área resolução de casos é um espaço de trabalho oferecido ao participante para a redação final de sua análise e proposta de solução. Trata-se de um formulário com características de processador de texto e de editor de mensagens, que contém três áreas de trabalho: a) definição do problema, onde o aluno deverá ele mesmo explicitar e fundamentar a natureza do problema (uma espécie de diagnóstico justificado); b) análise do problema, onde o aluno deverá levantar as possíveis causas e características do problema; c) discussão e conclusão, onde o aluno irá propor caminhos ou soluções para a situação apresentada, elaborando uma justificativa que deixe transparente o raciocínio que o levou à tomada de decisões sobre o caso.

O curso oferece, também, outras abordagens de trabalho com as situações-problema, como casos co- operativos, para trabalho em pequenos grupos. Além disso, os alunos recebem créditos pela elaboração de casos baseados em seus próprios contextos de trabalho, e aqueles considerados mais significativos por um comitê formado por tutores e alunos são incorporados ao curso. Periodicamente, há uma lista de discussão sobre um determinado caso, aberta aos participantes e sob a coordenação de um especialista na área.

\section{SISTEMAS DE AVALIAÇÃO}

O processo de avaliação é constante. Orientadores e participantes são encorajados a adotar uma atitude favorável à avaliação e auto-avaliação permanentes como princípio fundamental. No entanto, foram desenvolvidos três sistemas de avaliação para monitorar a qualidade do programa: 1) avaliação do progresso do aluno para fins de certificação e monitoramento do programa de educação continuada, que inclui a definição de parâmetros de qualidade e quantidade para o desempenho do aluno na resolução de casos, elaboração de casos novos, projetos em grupo e projeto final de curso; 2) avaliação do programa e da dinâmica do curso pelo aluno e pelo tutor, um espaço para que os participantes avaliem a qualidade do material, a orientação recebida, as formas de participação e a dinâmica do programa de formação; e 3) avaliação "gerencial" do programa, que integra a análise do fluxo de informações (estatísticas), diagnóstico de problemas acadêmicos e técnico-operacionais, análise de histórico escolar e de custo-benefício.

\section{CONSIDERAÇÕES FINAIS}

O modelo do CGDRHS, desenvolvido com a participação de profissionais das áreas da saúde, educação e tecnologia do Brasil, Chile e Peru, sob a coordenação do Programa de Desenvolvimento de Recursos Humanos da OPAS, vem sendo submetido a uma série de estudos pilotos. A versão em português foi avaliada com profis- 
sionais da rede de serviços de saúde na região Nordeste do Brasil. Com base nos depoimentos coletados por meio de entrevistas semi-abertas com orientadores e coordenação e, também, nas respostas dos alunos a um questionário com perguntas fechadas e abertas, veiculado na Internet, foram realizados vários ajustes que contribuirão para o aperfeiçoamento do sistema.

A versão em espanhol foi avaliada através de dois estudos pilotos realizados no Chile e no Peru. O do Chile foi conduzido pela divisão de recursos humanos do Ministério da Saúde e o do Peru esteve a cargo da Escola de Saúde Pública da Universidade Cayetano Heredia. Depois dessas avaliações, uma série de adaptações vêm sendo realizadas para facilitar, principalmente, o processo de implementação definitiva do curso e, sobretudo, para adequá-lo às reais condições de funcionamento em cada país.

As estratégias de divulgação e de seleção das instituições a integrarem o sistema como gerenciadoras do curso nos diferentes países serão objeto de discussão das reuniões do grupo de desenvolvimento do projeto, liderado pelo pessoal de recursos humanos das representações locais da OPAS.

O desenvolvimento e implementação de programas de educação a distância nos conduz a uma intensa reflexão neste momento em que a tecnologia torna-se fundamental para o avanço e crescente utilização em várias áreas e níveis de conhecimento. Por um lado, há aqueles que colocam as novas tecnologias no centro das atenções do processo educativo, como se fossem capazes de resolver todos os problemas da educação e da formação permanente da força de trabalho. Muitas vezes, esses incorporam modelos e práticas de forma acrítica, importando tais práticas de outras culturas, independentemente de sua viabilidade, pertinência e real contribuição aos contextos locais. Por outro lado, há aqueles que se negam a admitir que estamos em meio de profundas transfor- mações sociais, desencadeadas pelos avanços no campo da comunicação e da informação, que têm possibilitado novas formas de participação e experiências de aprendizagem, bem como novas demandas para o mundo do trabalho.

A partir dessas duas interpretações, entendemos que aprofundar sistematicamente o conhecimento nesse campo, avaliando suas potencialidades, experimentando novos modelos de comunicação no processo pedagógico, pesquisando a aprendizagem com esses meios, e analisando o impacto de sua utilização na educação permanente (especificamente em recursos humanos em saúde), é fundamental para construir um saber que coloque essas inovações a serviço do desenvolvimento intelectual e social dos indivíduos da nossa sociedade e da melhoria da qualidade da atenção à saúde da população. O Curso de Gestão Descentralizada de Recursos Humanos em Saúde é uma iniciativa nesse sentido.

\section{REFERÊNCIAS}

1. Staninger SW. Hypertext technology: educational consequence. Educ Technol 1994;34(7): 51-53.

2. Jacobs G. Hypermedia and discovery based learning: a historical perspective. Br J Educ Technol 1992;23(2):113-121.

3. Duffy TM, Jonassen DH. Constructivism: new implications for instructional technology. Em: Duffy TM, Jonassen DH. Constructivism and the technology of instruction: a conversation. Hillsdale, NJ: Lawrence Erlbaum; 1992. p. 1-16.

4. Wilson BG, ed. Constructivist learning environments: case studies in instructional design.
Englewood Cliffs, NJ: Educational Technology Publications; 1995.

5. Cunningham DJ, Duffy TM, Knuth RA. The textbook of the future. Em: McKnight C, Dillon A, Richardson J, eds. Hypertext: a psychological perspective. New York: Ellis Horwood; 1993. p. 19-49.

6. Bednar AK, Cunningham D, Duffy TM, Perry JD. Theory into practice: How do we link? Em: Duffy TM, Jonassen DH, eds. Constructivism and the technology of instruction: a conversation. Hillsdale, NJ: Lawrence Erlbaum; 1992. p. 17-34.
7. Honebein PC. Seven goals for the design of constructivist learning environments. Em: Wilson BG, ed. Constructivist learning environments: case studies in instructional design. Englewood Cliffs, NJ: Educational Technology Publications; 1996. p. 11-24.

8. Gutierrez F, Prieto D. A mediação pedagógica: educação à distancia alternativa. Campinas: Papirus; 1994.

Manuscrito recebido em 12 de março de 2001. Aceito em 26 de dezembro de 2001.

ABSTRACT This paper describes the Course on Decentralized Management of Human Resources in Health Care, which is an Internet-based distance learning program to train and provide continuing education for health care professionals. The program is an initiative of the Pan American Health Organization, and it was organized in response to the growing need for self-reliant professionals who can constantly upgrade their knowledge without having to leave their place of work. The proposed model promotes an educational process that brings together theory and practice in realistic and relevant contexts and that maximizes the participation of students, both individually and in groups. The program has been evaluated in pilot studies in Brazil, Chile, and Peru. Following these assessments, the course has been adapted to facilitate its implementation and to adjust its contents to fit each country's circumstances. 